\title{
Experimental Study of Cement Mortar Beam Strengthened by SMA Wires
}

\author{
Lee Seung Jo ${ }^{1, a}$, Park Jung Min ${ }^{2, b}$ \\ ${ }^{1}$ Department of Architecture, Chosun College of Science \& Technology, Gwangju, 501-744, South \\ Korea \\ ${ }^{2}$ Department of Architecture, Kyungbuk College, Yeongju, 750-712, South Korea \\ aemail: Isj3948@daum.net, bemail: green55glee@daum.net
}

Keywords: Shape Memory Alloy; High Intelligent Concrete; Heating, Garnet

\begin{abstract}
In this study, six highly intelligent reinforced cement mortar (HIRC) test specimens were fabricated by reinforcing the cement mortar with garnet, fiber (nylon and polypropylene), and shape memory alloy (SMA). The objective was to examine the effects of the number and position of the reinforcements on the physical characteristics of the SMA. The SMA-01 and SMA-02 test specimens abruptly failed after their maximum yield strengths were reached, with the latter's yield strength $54.2 \%$ higher than that of the former. In the test specimen with both the garnet and fiber, the yield strength gradually decreased after the maximum yield strength was reached, indicating a very good ductile effect. Under the load, the garnet and fiber first shared the yield strength against the crack resistance and increasing strength, after which the SMA shared the stress to show good structural self-rehabilitation capability. In improving the yield strength and structural self-rehabilitation capability, two or more hybrid fiber, PP and SMA reinforcements, as in SMA-PP-02, SMA-NP-02, and SMA-NP-01, yielded better results than SMA-01, SMA-Ny-01, and SMA-02.
\end{abstract}

\section{Introduction}

When a shape is made with the shape memory alloy, referred to as a smart material, and is subsequently memorized and cooled, it does not go back to its original shape when deformed below the martensite transition temperature. Rather, it recovers its original shape if it is heated above the austenite transition temperature. Since the discovery of SMA in 1951, the technology for self-rehabilitation assessment has been continuously developing with increasing use for dampers and monitoring for RC structures [1][2]. By using the constrained recovery effect, the researcher [3] used iron-based SMAs to transfer corrective forces to a RC bridge with beams lacking sufficient shear strength. To date, there is little data on the deflection control of a concrete beam eccentrically embedded with SMA wire actuators in current literature [4]. Existing studies [5], however, are mostly about the simple general RC structures. There are few studies about the fiber-reinforced HIRC that contains eco-friendly admixture materials and fiber that has crack control effect. In this study, the effects of mixing SMA, garnet, nylon and polypropylene, and of the reinforcements with hybrid fiber and SMA on the HIRC were examined and compared in terms of the crack control effect and bending strength test results before and after the self-rehabilitation.

\section{Experimental}

\section{Materials}

The results of the analysis of the garnet, nylon, and polypropylene were taken from preceding studies [6]. Table 1 shows the transition temperatures by stage and physical characteristic for the NiTi SMA. Table 2 shows the mixing characteristics according to the water-binder ratio and the components. Two SMA reinforcements were applied to SMA-PP-02, SMA-02, and SMA-NP-02.

\section{Apparatus and procedures}

A vibrate combination mixer used to mix mortar based on KS L 5109 and ASTM C 348 for bending strength was used for the experiment. Figure 3 shows the overall diagram of the bending strength test, while Figure 4 shows the internal arrangements of the SMA wires. 


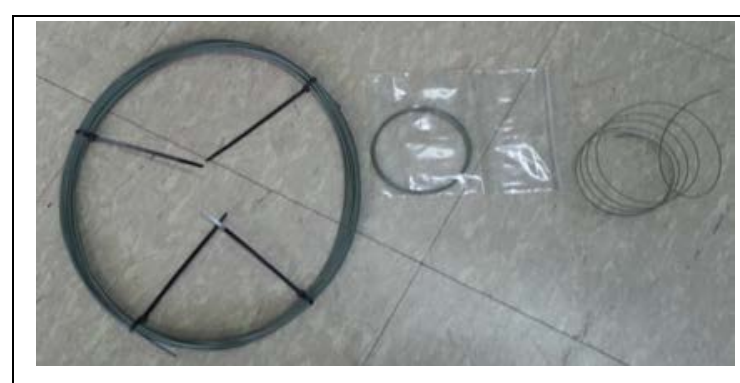

(Shape Memory Alloy)

Fig. 1 SMA

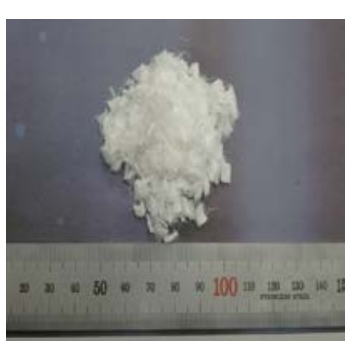

(Ny)

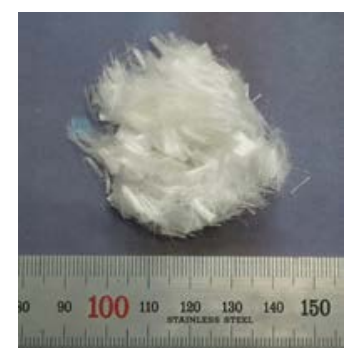

(PP)

Fig. 2 Fibers used in this study

Table 1 Phase trasition temperature of NiTi SMA and Physical properties of SMA

\begin{tabular}{|c|c|c|c|c|c|c|c|c|}
\hline \multicolumn{2}{|c|}{} & \multicolumn{4}{|c|}{ Physical properties } \\
\cline { 2 - 5 } & $\begin{array}{c}\text { Elasticity } \\
\text { modulus } \\
(\mathrm{MPa})\end{array}$ & $\begin{array}{c}\text { Tensile } \\
\text { strength } \\
(\mathrm{MPa})\end{array}$ & $\begin{array}{c}\text { Yield strength } \\
(\mathrm{MPa})\end{array}$ \\
\hline $\mathrm{M}_{\mathrm{f}}$ & $\mathrm{M}_{\mathrm{s}}$ & $\mathrm{R}_{\mathrm{f}}$ & $\mathrm{R}_{\mathrm{s}}$ & $\mathrm{A}_{\mathrm{s}}$ & $\mathrm{A}_{\mathrm{f}}$ & 2200 & 1300 & 521 \\
\hline 9.9 & 28.7 & 42.8 & 52.1 & 60.1 & 71.2 & 200 & \multirow{2}{|c|}{ Phase transition temperature $\left({ }^{\circ} \mathrm{C}\right)$} & \\
\hline
\end{tabular}

Table 2 Mixing properties composition of $\mathrm{W} / \mathrm{B}$ ratios and materials

\begin{tabular}{|c|c|c|c|c|c|c|c|c|c|}
\hline \multirow{2}{*}{ Specimens } & \multirow{2}{*}{$\begin{array}{l}\text { W/B } \\
\text { (\%) }\end{array}$} & \multirow{2}{*}{$\begin{array}{l}\text { GA } \\
\text { (\%) }\end{array}$} & \multirow{2}{*}{$\begin{array}{l}\mathrm{Ny} \\
(\%)\end{array}$} & \multirow{2}{*}{$\begin{array}{l}\text { PP } \\
\text { (\%) }\end{array}$} & \multirow{2}{*}{ SMA } & \multicolumn{4}{|c|}{ Materials $\left(\mathrm{kg} / \mathrm{m}^{3}\right)$} \\
\hline & & & & & & Cement & GA & Sand & Water \\
\hline SMA-01 & \multirow{6}{*}{57} & None & None & None & 1 & 290.9 & None & 616 & \multirow{6}{*}{162} \\
\hline SMA-Ny-01 & & 20 & 1.2 & None & 1 & 232.7 & 58.2 & 616 & \\
\hline SMA-PP-02 & & 20 & None & 1.2 & 2 & 232.7 & 58.2 & 616 & \\
\hline SMA-02 & & None & None & None & 2 & 290.9 & None & 616 & \\
\hline SMA-NP-01 & & 5 & 0.1 & 0.4 & 1 & 344.4 & 18.1 & 727 & \\
\hline SMA-NP-02 & & 20 & 0.4 & 0.8 & 2 & 232.7 & 58.2 & 616 & \\
\hline
\end{tabular}
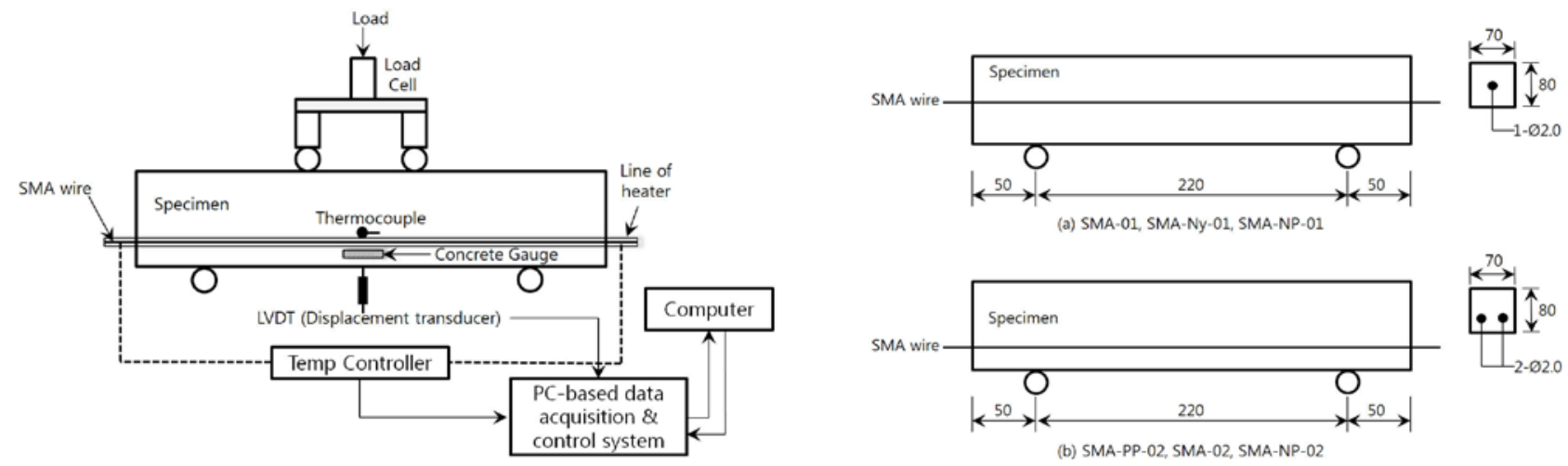

Fig. 3 Instrumentation sketch

Fig. 4 Schematic of specimen with embedded SMA wires 

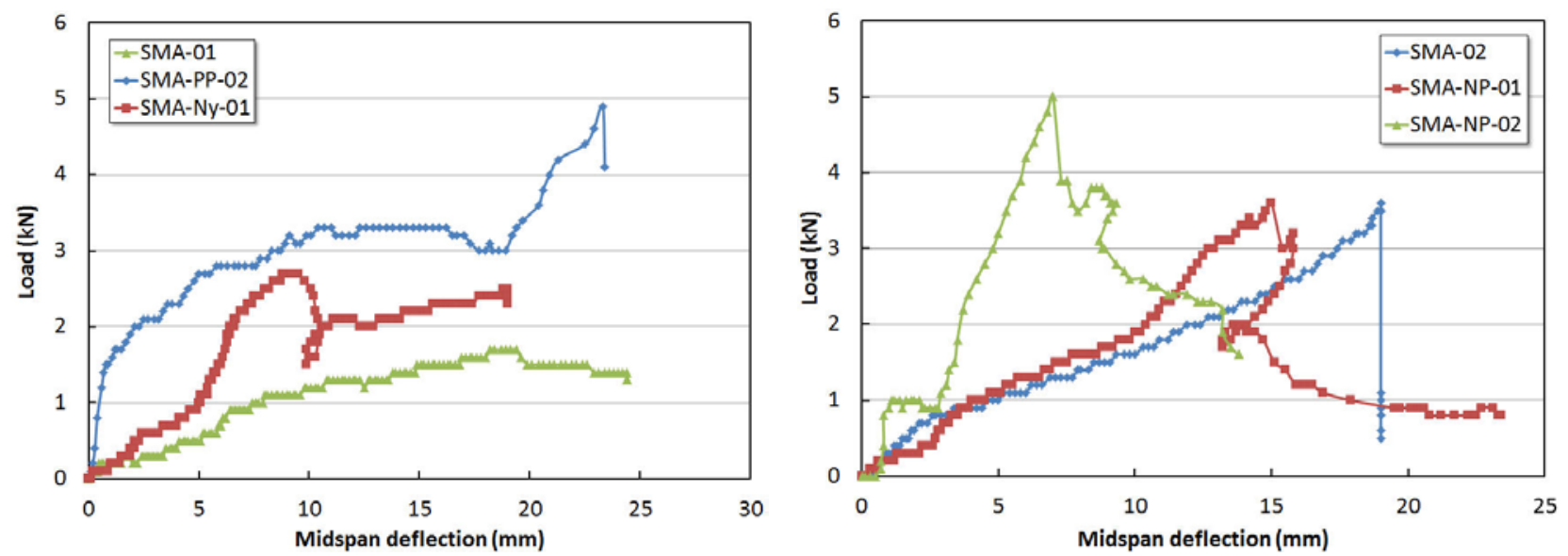

Fig. 5 Load versus midspan deflection curve of specimen
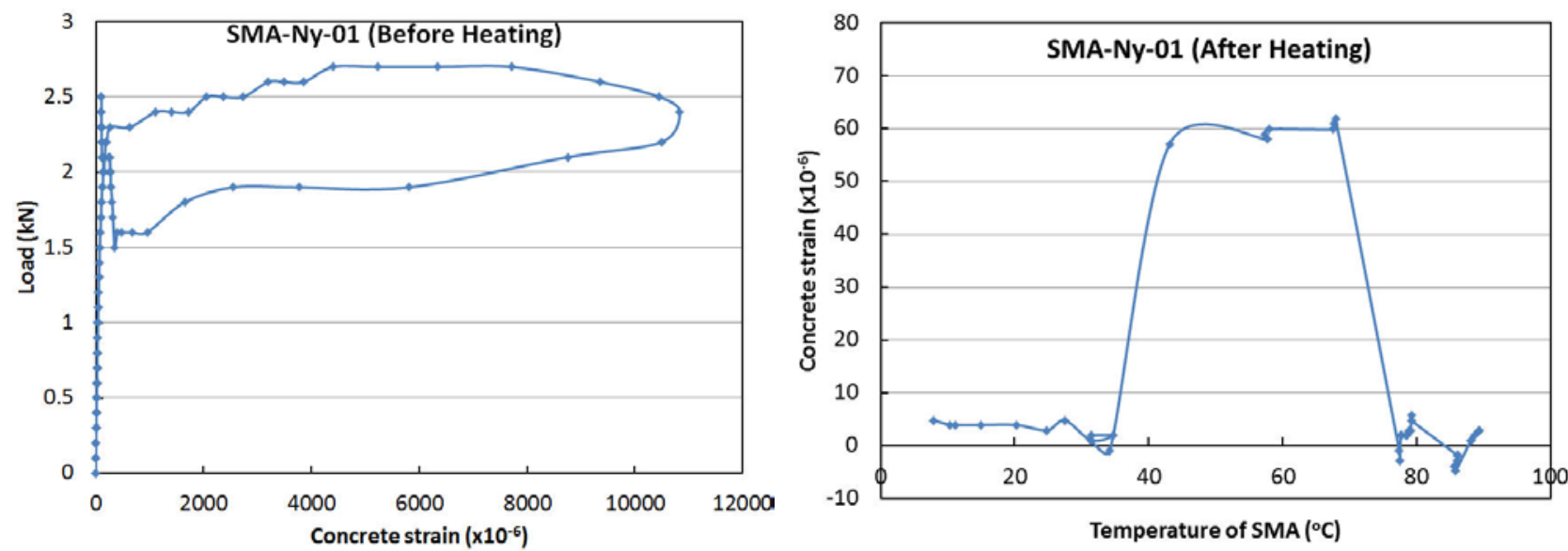

Fig. 6 Load versus concrete strain curve

Fig. 7 Concrete strain versus temperature of SMA

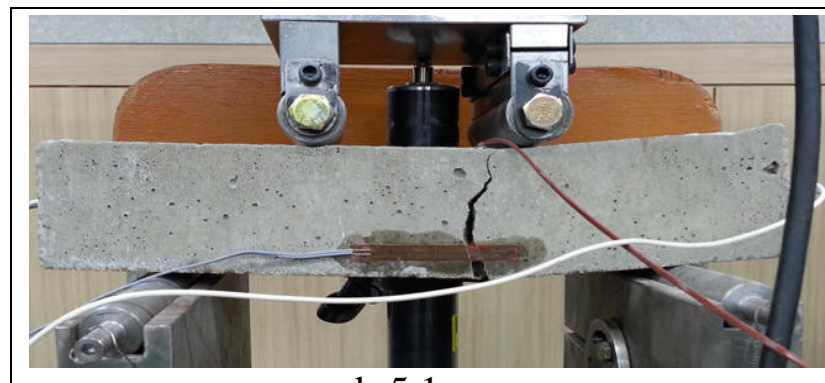

$\mathrm{d}=5.1 \mathrm{~mm}$

Before activation of SMA

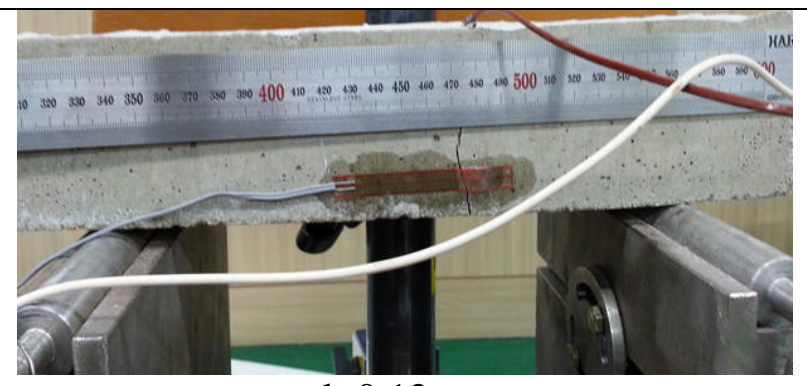

$\mathrm{d}=0.12 \mathrm{~mm}$

After activation of SMA

\section{Fig. 8 Crack pattern of specimen SMA-01 actuated by SMA wires}

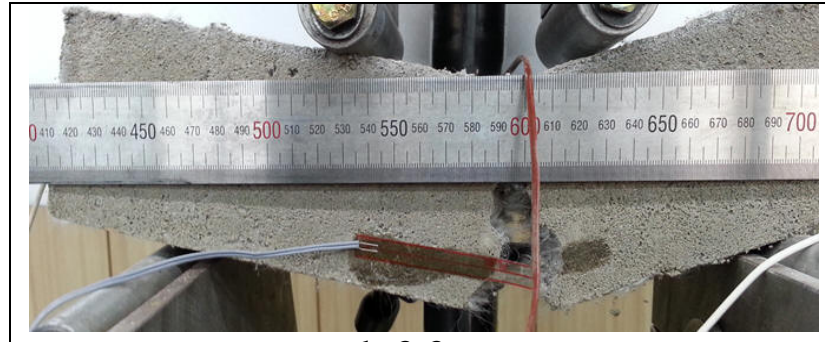

$\mathrm{d}=3.3 \mathrm{~cm}$

Before activation of SMA

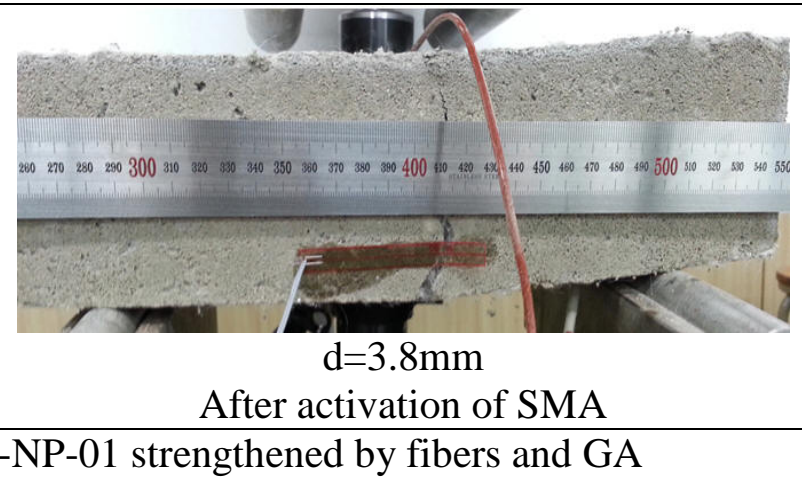

After activation of SMA

Fig. 9 Crack pattern of specimens SMA-NP-01 strengthened by fibers and GA 


\section{Results and discussion}

Figure 5 shows the load-center deflection curve. The SMA-PP-02, SMA-02, and SMA-NP-02 test specimens showed continuously increasing loads, together with the significantly increasing center deflections after exceeding the elastic range. The test specimen with two SMA wires at the lower part had a 45-55\% higher maximum strength and a better ductile effect than the test specimen with only one SMA wire at the center. With the increase in the load, concrete deformation also increased, and showed an elliptical curve after specimen failure as seen in Figure 6. With the increase in temperature inside the test specimen, concrete deformation also increased and then abruptly decreased after the austenite transition temperature was reached, as shown in Figure 7. In the SMA-01 test specimen, the crack width was $0.51 \mathrm{~cm}$ before heating, but decreased to $0.012 \mathrm{~cm}$ after heating, as shown in Figure 8. In the SMA-NP-01 test specimen, the crack width was $3.3 \mathrm{~cm}$, but it decreased to $0.38 \mathrm{~cm}$ after heating, as shown in Figure 9. This appears to be because the SMA was mixed with the specimen to control the crack, that is, to improve the structural self-rehabilitation capability of the specimen.

\section{Conclusion}

(1) The test specimen that had no fiber or garnet, or that had only one SMA, had a low maximum bending strength. In the same condition, the bending strength of the test specimen varied according to the number and position of the SMA wires. The test specimen with SMA wires at the lower part had a high bending strength. A further comparative study of the arrangements of the existing reinforcements is needed based on the results of this study.

(2) The test specimens that had only one SMA wire at the center had 0.51-3.3cm maximum crack widths, but those that had two SMA wires at the lower part had $0.5-2.7 \mathrm{~cm}$ maximum crack widths. This indicated that two or more reinforcements greatly improved the self-rehabilitation capability of the test specimens. The application of the SMA significantly influenced the crack width and self-rehabilitation capability of the deflection at the center.

\section{Acknowledgment}

“This research was supported by Basic Science Research Program through the National Research Foundation of Korea (NRF-2014R1A1A2059498) funded by the Ministry of Education, Science and Technology"

\section{References}

[1] Toshinori Takagi: Concept of Intelligent Materials, Intelligent Materials Systems and Structures [J], 1990 1149-1156.

[2] Gangbing Song: Applications of Shape Memory Alloys in Civil Structures [J], Engineering Structures, 2006 (28)1266-1274.

[3] Parviz Soroushian: Repair and Strengthening of Concrete Structures through Application of Corrective Posttensioning Forces with Shape Memory Alloys. Transport Res Rec 1770, 2001, Paper no. 01-0400.

[4] Arup K Maji: Smart Prestressing with Shape-Memory Alloy [J], ASCE-Journal of Engineering Mechanics, 1998 (10) 1121-1128.

[5] K. Otero: Intelligent Reinforced Concrete Structures using Shape Memory Alloys. M.S.thesis. Advisor: Dr. G. Song, University of Houston, 2004.

[6] Seung Jo Lee: Properties of Hybrid Fiber Reinforced Cement Mortars as a Function of Type of Fiber [J], Advanced Materials Research, 2014 (935) 142-145. 